\title{
SHAPE OF PROFESSIONAL PRACTICE RESEARCH
}

\author{
Samuel Mann
}

\section{INTRODUCTION}

Postgraduate professional research and learning can be described as "surfing the edge of chaos" (Mann et al., 20 I7). It sits at the intersection of learning, research and work - all of which have different environments, practices and languages. In traditional postgraduate research, centuries of development have led to a strong set of conventions - the candidate, supervisor, proposal and thesis are all terms that are well understood. However, in the much newer field of professional practice, many of these terms are eschewed in favour of terms that better reflect the relationships and processes involved. Hence supervisors are mentors, the proposal is a learning agreement, and so on. But beyond these terms, the nature or 'shape' of professional practice research is not well understood. This is a problem as staff and learners strive to build shared understandings; or as we attempt to describe innovations in processes, align with standard quality assurance mechanisms, define transformations or even provide baselines against which innovations can be considered.

In this paper I describe the overall process of a professional practice journey, and ground this with reference to results from a survey of graduates of a Master of Professional Practice at Otago Polytechnic (MProfPrac).

\section{METHOD}

I surveyed MProfPrac graduates who completed between 2014 and 2018 to better understand their journey $(n=24)$. The survey was emailed to 79 graduates using their last known email address. Ten were returned by the mail system as having an invalid address, giving an effective return rate of $34.78 \%$. The survey was approved following Otago Polytechnic Category B Delegated Ethics processes.

The survey was introduced as follows: "Our goal is to improve the tools for describing the 'shape' of Professional Practice learning/research journey. By 'shape' we mean the available choices in structure and approach, rather than your particular questions or subject area. We have focused here on the Learning Agreement and Practitioner Inquiry stages of the process."

Capable NZ's MProfPrac follows a learner-determined heutagogical approach. The learner is experienced, and is combining existing work practice knowledge with new learning to articulate their new professional framework of practice.

Hase and Kenyon (2000) place responsibility for heutagogy with the student, where they are able not only to engage in a process of knowledge creation, but also have the opportunity to determine their learning experience under the influence of their professional practice. Otago Polytechnic has adopted a heutagogical-based teaching and learning strategy that has a radical impact for education. Exemplifying this methodology is the work-based learning approach of Capable NZ (the professional practice school within Otago Polytechnic). Capable NZ works with learners to recognise and extend learning in a professional work-based context at both undergraduate and postgraduate levels. 
At undergraduate levels, Capable NZ works with learners to align their professional framework of practice - their professional identity - with graduate profiles. These learners are expected to learn new areas, mostly to wrap their practice in theoretical context, but there are no formal classes. Instead the focus is on an individualised supportive environment for personal reflection.

The goal is the advanced professional framework of practice (Figure I). This is articulated in a 'practitioner thesis,' where the defensible argument is that professional framework of practice. The process starts with a review of learning that leads to stating the learner's aspirational framework of practice (e.g., "to become a thought leader in values-driven software development"). This is paired with an organisational practice goal (e.g., "to create a culture of values-driven software development"). The main work then becomes the professional development thread, interwoven through reflective practice with the work-based professional practice change (usually formally described as "autoethnographic action research"). Learners are supported by academic and professional mentors. The graduate profiles for both the Doctor of Professional Practice (DProfPrac) and the MProfPrac are written in terms of higher levels of thinking in a post-disciplinary sense, rather than for specific disciplines.

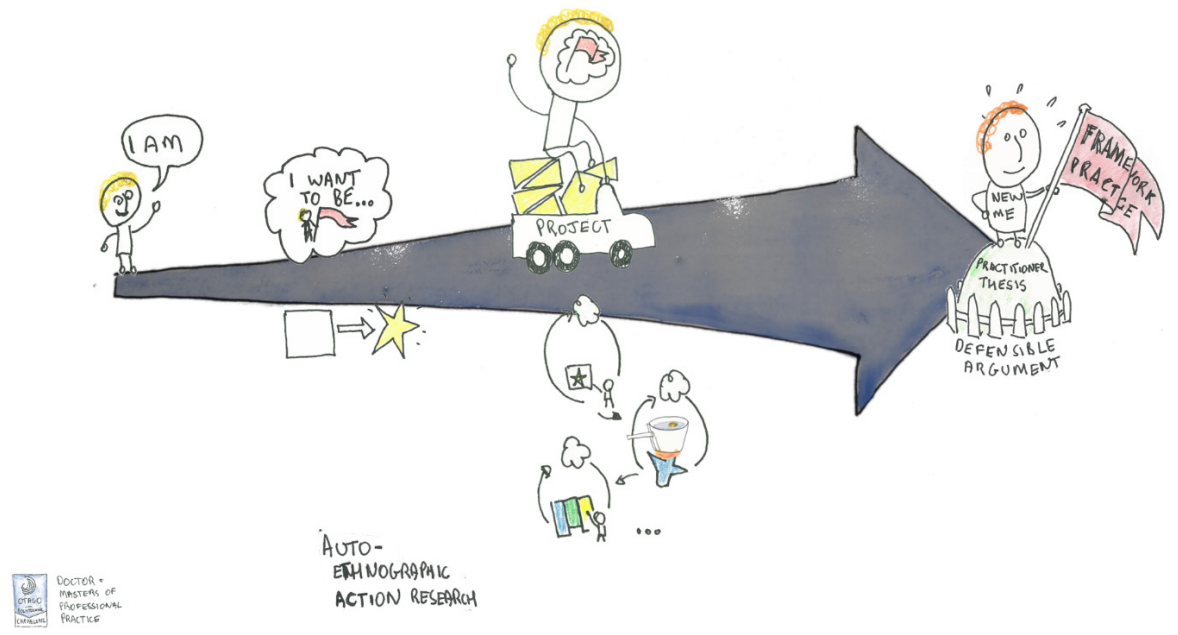

Figure I. Overview of Professional Practice pathway, from a review of learning, "I am," through a Learning

Agreement, "I want to be ..." and project inquiry to a final practitioner thesis and presentation.

\section{LEARNER JOURNEY}

\section{Work}

Eighty-one percent of respondents described their context as being "in work" and 13\% undertook the study as part of a work "transition." For most, the area of focus was a combination of an "area of passion" and a "work opportunity," and this is reflected in the origin of the research question, with $60 \%$ of these coming from practice
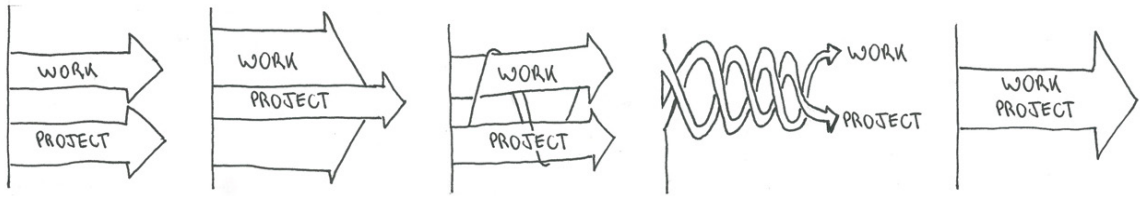

Figure 2. Relationships between work and project. Eighty percent of respondents chose the two right-hand options as describing the relationship between their work and their project. 
and a further $20 \%$ coming from a mismatch of theory and practice. Most (72\%) saw their research project as intertwined with their work and a further $18 \%$ saw "work and project as the same thing." Only $9 \%$ saw their "project as being in the same space as their work, but isolated," and none saw the two as separate (Figure 2).

The close connection between work and study aligns with Lester's (2004) "engagement in advanced learning leading to major organisational change and/or excellence in professional practice" (p. 6). Lester argued that such learning and research are unavoidably taking place in the "mess of practice" (p. 7), and that what is needed are appropriate methods that provide robustness and rigour in that mess and of that mess - not seeking to dampen the messiness of practice by imposing inappropriate research paradigms. This was recognised by the respondents: 53\% saw the "messiness of everyday practice as their research," and 37\% said their research accommodates this messiness (Figure 3).
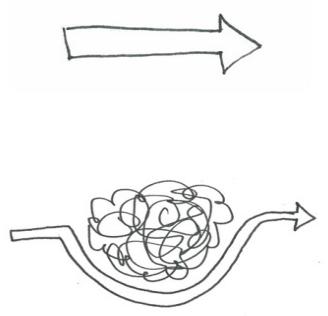
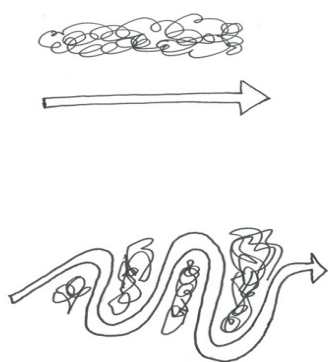
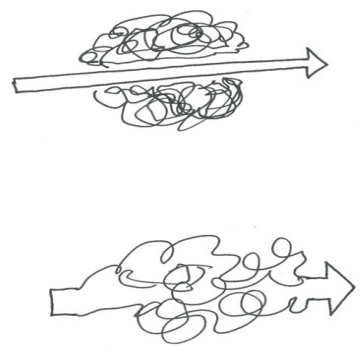

Figure 3. The relationship between the "messiness" of everyday practice and the research project. Ninety percent of respondents picked either of two options: "accommodates messiness" or "messiness as research," describing their

MProfPrac (lower middle and right).

Expanding Gibson's 1994 typology of knowledge, Scott et al. (2004) describe how Mode 2 knowledge is produced in the context of application. Such research has an expansionist approach to problem solving, and has a distinguishing feature that developers of knowledge will also apply it. This can be seen in the origin of the research question. None of the respondents described their research question as coming "from literature" alone - "I examined it through my practice." Seventy percent described it as coming "from practice, I positioned that in the literature. Ten percent said it was common to both practice and literature, and 10\% described a mismatch: "The area is well understood in theory, but questions arise when the practice dimension is added."

\section{Paradigms and ologies}

Stock (20ll) described an "ongoing fundamental shift of opening up alternative modes of knowledge and discovering for academic research." These alternative modes of knowledge raise questions of paradigm, approach, and epistemology and ontology.

Of our MProfPrac graduates, $83 \%$ took a systems (rather than reductionist) approach. Eighty-two percent reported that their research was either cross-, inter- or transdisciplinary (even after being instructed that adding education and a practice lens did not make it multidisciplinary); $18 \%$ said it was contained in a single discipline.

We asked the MProfPrac graduates to describe the paradigm (Figure 4) that they followed for their practice project, and separately for their learning project (Figure 5). It was interesting to note that the graduates reported different paradigms for the two aspects (Figure 6). For example, an engineer might have a positivist project that is wrapped in a constructivist learning experience. We believe that the key to successful professional practice research is being able to describe these two aspects and how they fit together. 
POSITIVISM

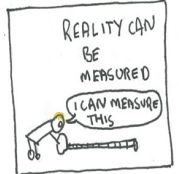

PRAGMATISM
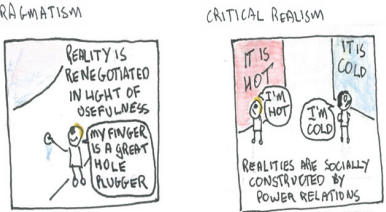

CONSTRUCTIUISM

IINEERPRETIVISM

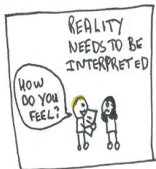

POST MDDERNISM

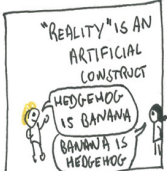

Figure 4. Research paradigms. These were sought twice of the MProfPrac graduates in the study, for the practice project and for their learning project.

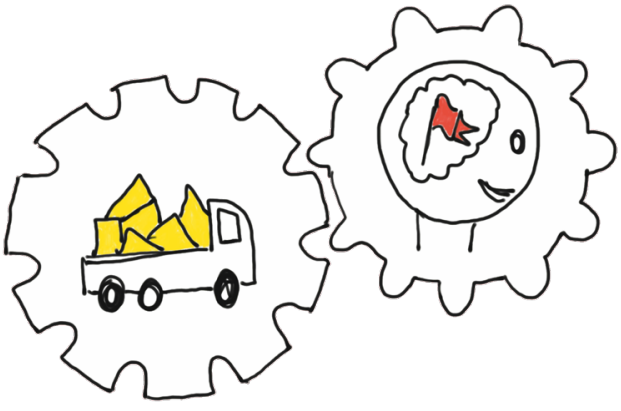

Figure 5. Respondents described different paradigms for the work project and learning project aspects of their MprofPracs.

$\left\{\int_{000}^{200}\right\}$ Positinism
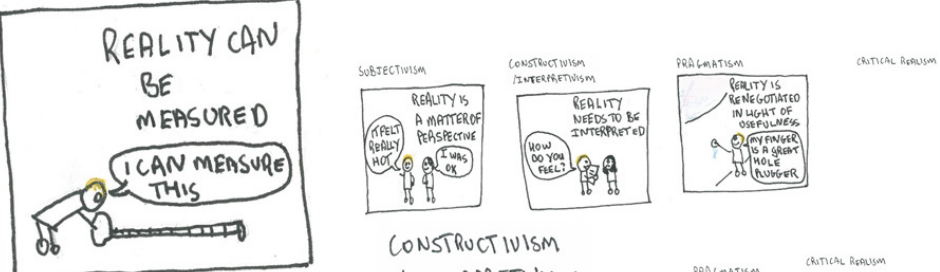

POST MEQRRNism

CONSTRUCTIUISM

IINTERPRETINISM
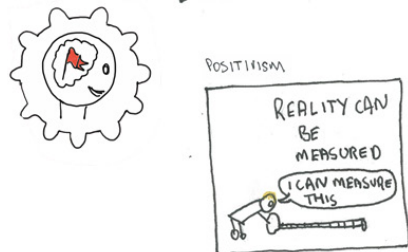

Subsectivism

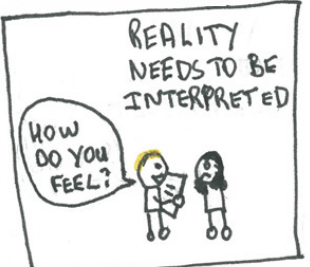

PRALmaTison

CRITLAL REFUSM
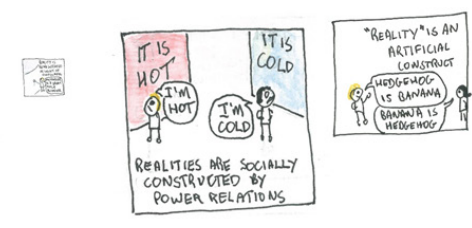

Figure 6. Research paradigms: the practice project (top line) and the learning project (bottom line). Image sizes represent frequency of responses.

\section{Maturity}

A capability maturity model was used to ascertain the role of ethics, sustainability and kaupapa Māori (Table I). While most respondents fell in the 'apply' or higher categories, there were a considerable number in the 'comply' (required) or avoid categories, particularly for kaupapa Māori. 
Table I. Capability maturity model for underpinning frameworks.

\begin{tabular}{|l|l|l|l|l|l|}
\hline & Avoid & Comply & Apply & Reason & Passion \\
\hline Ethics & $0 \%$ & $11 \%$ & $33 \%$ & $39 \%$ & $17 \%$ \\
\hline Sustainability & $6 \%$ & $29 \%$ & $12 \%$ & $24 \%$ & $29 \%$ \\
\hline Kaupapa Māori & $11 \%$ & $33 \%$ & $11 \%$ & $39 \%$ & $5 \%$ \\
\hline
\end{tabular}

\section{Uncertainty}

Stock (20II) described how professional practice research replaces propositional with emergent knowledge, where approaches and findings "may encompass paradox, ambiguity and uncertainty."

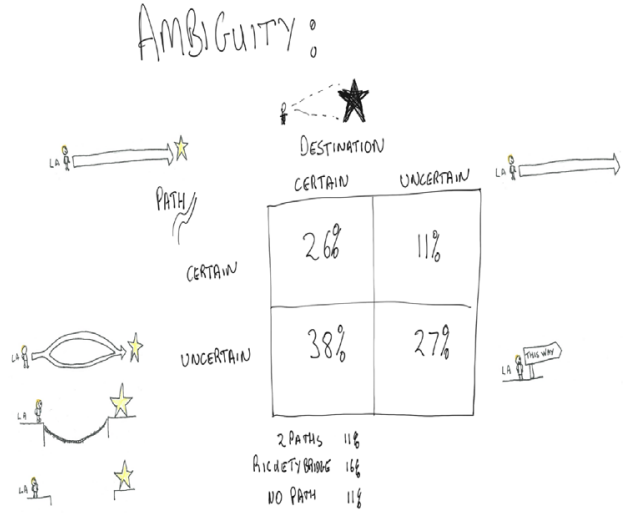

Figure 7. Levels of uncertainty in path and destination reported at the end of the Learning Agreement.

Given that they described projects characterised by inherent messiness of practice, we asked the graduates to state the extent to which their research was ambiguous at the end of their learning agreement stage, as it related to both destination and path of research. Twenty-six percent reported certainty in both destination and research: "I know where I'm going and I know how l'm going to get there." Eleven percent had a certain path, but an uncertain destination. Thirty-eight percent had a certain destination, but an uncertain path - variations on "I know where I'm going, but there's a rickety bridge to cross," or "there's a couple of paths I want to try out." A further $27 \%$ reported being well-equipped adventurers: "I'm well equipped, I know how to climb mountains, let's go ..." (Figure 7). We would expect this level of uncertainty and ambiguity to be a challenge to those assessing the Learning Agreement, whose experience lies in more conventional approaches. We suggest there may be benefit in framing projects according to approaches such as Agile, that explicitly embrace change (Wells and Smyth, 20I6; Zaitsev et al., 20 I8).

\section{Reflection}

A key concept in heutagogy is that of double-loop learning and self-reflection (Hase \& Kenyon, 2000). In doubleloop learning, learners consider the problem and the resulting action and outcomes, in addition to reflecting upon the problem-solving process and how it influences the learner's own beliefs and actions.

Respondents were asked how often they recorded their reflections. Forty-two percent said "whenever something interesting happens," and 31\% said "about once a week." The daily, twice a week and once a month respondents all recorded II\%. This question asked them to pick one, but there were several comments to the effect that: "I had a rule that I would record whenever something interesting happened, but at least once a week." Respondents were presented with 22 potential activities that described "the most useful activities in reflection." All except social media, watching TV and "videoing myself talking" were selected. The highest responses of I I\% were for "taking notes whenever something interesting happened,"' "reading" and "short notes on computer." Future research should focus on the nature and contribution of reflection. 


\section{End game}

In the context of doctoral study, there is much written on the concept of 'doctorateness' - the level at which the learner is making the claim. There is almost nothing on the equivalent level for masters level - masterness? (note, not mastery - that is something else) - but it is a common question posed by assessors at the learning agreement stage - how will you know when you've done enough?

Respondents were asked: "How did you know it was time to move from a focus on practice to writing up the final report?" (with the clarification "if it was because your mentor said so, what was their justification?"). Fifty-eight percent responded that while the project was ongoing, they either "had reached the point that I could articulate my framework of practice" (42\%) or "had enough material for my story" (16\%). Forty-two percent said the project had either "met a suitable milestone" or "had completed" (21\%). None reported that the due date was the driver, or that the project had failed or come to a premature end.

Respondents were asked to select an option that best described their experience. None selected: "it was a pretty straight path to where I planned." Twenty-one percent said: "there were a few diversions, but I managed to stay on track." Several options were offered as to how diversions were managed: "brought back into main thread" (5\%), "improved the overall story" (16\%), and "completed both stories" (5\%). Beyond diversions, we described "rabbit holes and spaghetti," which was selected by $37 \%$, of which $21 \%$ "ended up in line with where I was originally heading" and 16\% concluded "with a surprise ending."

The majority (52\%) of respondents reported that the work of the final report production was "stepwise but largely consistent" over the whole research period. Twenty-one percent said they "got a lot done early, but slowed after that." Only 16\% reported that "most of the writing got done at the end."

The process of writing the final report was also dominated by those who had written a good deal during the whole practitioner inquiry (53\%), made up of those who reported tidying reflections into chapters (32\%) or "notes informed a big reflective blender from which I wrote the final report" (21\%). Twenty-two percent reported developing the report structure early and adding material throughout the inquiry (I I\%) or writing sequentially (। ।\%).Twenty-one reported along the lines that "it kind of emerged, not sure how that happened."

With a focus on an autoethnographic approach, and the role of the learners' own journey, we were interested to see how this was expressed. We offered six narrative structures. The largest group was A Hero's Journey (47\%), $21 \%$ opted for collective narrative (multiple storylines), and between 5 and 10\% for Scandinavian narrative, Indian narrative, African central narrative and Autochthonous narratives.

Shaping the overall structure of the final report can be challenging for learners. Unlike the conventional thesis monologue structure, there is no widely accepted convention for a practice-led thesis. We refer to the final report as the practitioner thesis, and state that it must convey the work/project report and a critical reflective commentary. Thirty-three percent of respondents said that the project report and reflection on learning were "essentially separate documents;" $22 \%$ stated that their project was "headed and tailed by a reflective chapter;" $22 \%$ described two sections within each chapter; and 16\% stated that they weren't "separated at all, it was all integrated."

\section{Impact}

We asked the graduates where their MProfPrac work had contributed - to practice, understanding, and so on. This was broken into the impacts stemming from the articulation of the professional framework of practice (flag on top row on Figure 8), change in their practice (building star, middle row), or the direct impact of the improvements made in their organisations (star, bottom row). 
We asked respondents which of the provided statements best aligned with the journey of their professional identity or professional framework of practice (this latter term we have only been using in the last few years). While $28 \%$ reported that their professional framework of practice was "as expected from my learning agreement," $44 \%$ responded that it had "greatly expanded from the aspirations described in my learning agreement." Sixteen percent described a "wild ride" for their professional framework and 17\% a "significant pivot."

We asked respondents to rate the relative importance of their final report and presentation of their professional framework, change in practice and their work's impact (we asked these separately; they could have said they were all most important). All three aspects were reported about the same level ("fully described and was a major contributor to my evidence"), averaging 2.83-3 on a four-point scale, although the "description of the impact I have had" achieved this with a wider spread (i.e., more respondents regarded it as either not a major contributor or "the most important evidence").

Mann (2017) concluded that further research should focus on the role of learning - did the learners know they were learning? Was it transformative? Here we contributed something to that question by asking respondents to identify their top three moments of learning (Figure 9, Table 2). It is interesting to note that learning opportunities can be found throughout the learning journey, rising to a peak after the formal end of the MProfPrac.

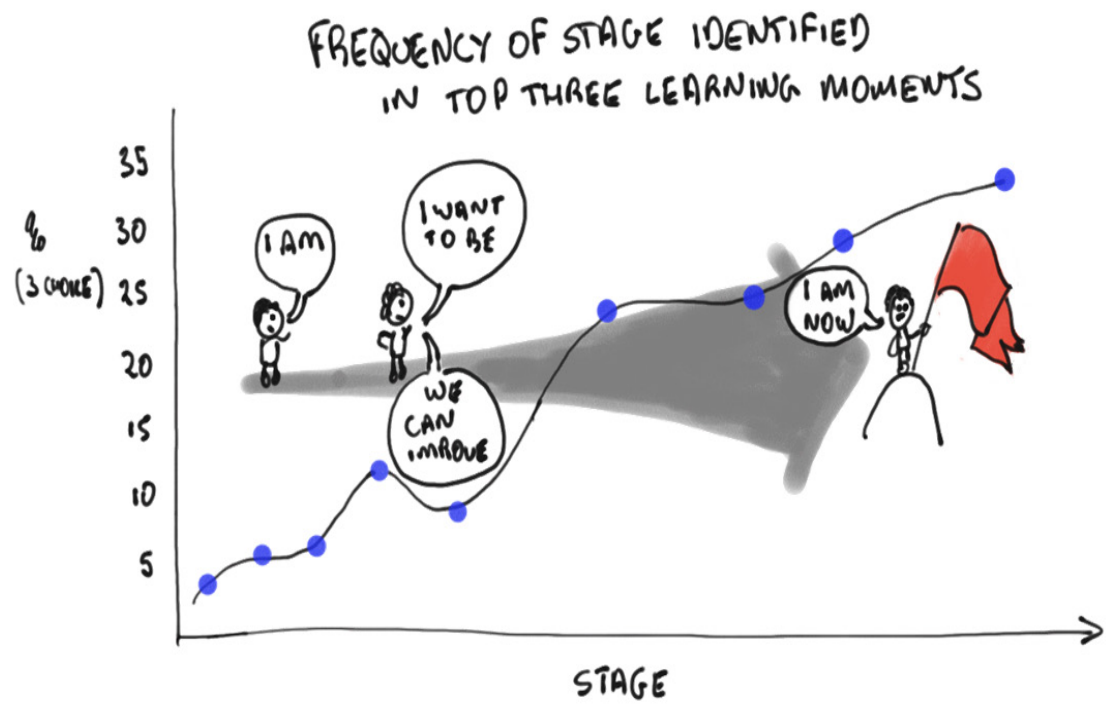

Figure 9. Most impactful moments of learning for MProfPrac learners (each respondent identified up to three such moments). 
Table 2. Examples of learning at different stages in the MProfPrac journey, as reported by graduates.

\begin{tabular}{|c|c|}
\hline Stage of MProfPrac & Examples of learning described by graduates \\
\hline Review of Learning & $\begin{array}{l}\text { - } \quad \text { Reflecting on my previous practice and recognising the informal } \\
\text { learning that had occurred. } \\
\text { - } \quad \text { Structuring my journey into the RoL }\end{array}$ \\
\hline Preparing Learning Agreement & $\begin{array}{l}\text { - } \quad \text { Looking into what exactly was I trying to address/improve/ } \\
\text { - } \quad \text { Onplore. } \\
\text { - } \quad \text { Extensive literature review of creativity and then a process } \\
\text { of contextualising those concepts into my practice as both a } \\
\text { teacher and audio engineer. } \\
\text { - Finding out for myself how the skills I have come to take for } \\
\text { granted are of high value in a business environment }\end{array}$ \\
\hline Learning Agreement & $\begin{array}{l}\text { - Then trying to understand what might my 'end state' would } \\
\text { look like - i.e., what difference was I trying to make both for } \\
\text { myself but also for my organisation? } \\
\text { - } \quad \text { Attention to detail with LA }\end{array}$ \\
\hline Starting Practitioner Inquiry & $\begin{array}{l}\text { - Deep reflection into my previous work in the context of my } \\
\text { current role } \\
\text { - } \quad \text { Finding the name for what I was doing and what I researching. } \\
\text { - Continuing to work on self-awareness and my place in the } \\
\text { communities I am a member of }\end{array}$ \\
\hline Middle of Practitioner Inquiry & $\begin{array}{ll}\text { - } & \text { Reflecting on survey of organisations and responses. } \\
\text { - } & \text { Systems thinking, that organisations crave leadership } \\
\text { - } & \text { My students that I interviewed - their responses were the most } \\
\text { significant learning } \\
\text { - } \quad \text { New offerings to measure authenticity }\end{array}$ \\
\hline End of Inquiry/finalising thesis & $\begin{array}{l}\text { - Reflecting on how I had shifted in some of my thinking and, } \\
\text { more importantly, in my practice. } \\
\text { - Proved concept in role, enquiry reinforced this and added more } \\
\text { relevance. Region has changed to adopt the concept. } \\
\text { Realising this is part of an ongoing process that will continue } \\
\text { long after the MPP has been completed. }\end{array}$ \\
\hline $\begin{array}{l}\text { Practitioner thesis and } \\
\text { presentation }\end{array}$ & $\begin{array}{l}\text { - Finally comfortable in my own skin as a competent professional } \\
\text { in my chosen field. } \\
\text { - Summing up the themes in my life - congruence finishing the } \\
\text { project and looking back on what I changed in my role in the } \\
\text { organisation. } \\
\text { - What I had learned about learning and what I learned about } \\
\text { my role }\end{array}$ \\
\hline After & $\begin{array}{l}\text { - Realising the extent of what the MPP meant to the breadth and } \\
\text { depth of that field } \\
\text { - } \quad \text { Realising the importance of service learning. It is now one of my } \\
\text { strengths, as my professional body informs me. } \\
\text { - Realising I had done a good piece of work that would be help- } \\
\text { ful for many. }\end{array}$ \\
\hline
\end{tabular}




\section{Framework approach}

We asked respondents to comment on whether the overall framework (Figure I) and questions (described above) "captured the overall shape of your experience"? All the comments were positive, including "good spread of the reality of the experience;"' "that's a really good way of articulating what I did;" and: "What was important for me was being encouraged and supported to think broadly about different ways to present my work: I was supported to move beyond the traditional idea of chapters and a thesis instead to what I felt would be most useful and applicable. This was a major positive for me."

Interestingly, several respondents added words to the effect that: "I think mine might have been a fairly unique case, with a major context change halfway through my study." Perhaps we need to better communicate that pivots and emergence are the norm, rather than the exception.

We asked what dimensions we had missed - with most replying to the effect that "it's all good." A few people wrote about personal transformation, and others mentioned the importance of the team (their mentors and colleagues) in the reflection and learning process.

\section{CONCLUSION}

In education, concepts such as constructive alignment provide a common language to describe learning design and learning journeys. But this language performs poorly when applied to heutagogically based self-determined learning such as professional practice, especially at higher levels such as postgraduate. This makes it difficult to describe innovations, align with standard quality assurance mechanisms, define transformations or even provide baselines against which innovations can be considered. Existing descriptions that go beyond the instrumental have focussed on autoethnographical accounts of individual learners' journeys which are insightful, but haven't provided the common language required. Others have explored business impacts or personal impacts, but rarely together. In this research we have introduced an approach that characterises both the learning (as transformation) and the process by which this is achieved. This paper has described a model of professional practice research and shows, through a survey of completed Masters of Professional Practice candidates, that it well describes the variation in approaches of the practice, learning and research nexus experienced.

Another area that this research has highlighted is a low level of self-reported maturity with regards to kaupapa Māori, with many reporting avoiding it or only compliance. New Zealand is founded on a partnership between the Crown and Māori. In Otago Polytechnic's case, this is manifest in a Memorandum of Understanding between the Araiteuru Papatipu Rūnaka (local indigenous people) and Otago Polytechnic. This underpins all of our activities, including that of Capable NZ. The Kāi Tahu vision document, "NgāiTahu 2025," stresses the importance of education as an enabler of wider goals, of tino rangatiratanga, in "the ability to create and control our destiny." A key driver is that "all initiatives and programmes must be future-orientated," and a key assumption is the integration of education. The key phrase here is "tino rangatiratanga," which means absolute sovereignty or self-determination. Despite an approach that is purposefully aligned with a Te Ao Māori approach, for many graduates this was not a feature of their work. Further research is needed in this area.

It would be useful to ask a similar set of questions of MProfPrac mentors and facilitators. Anecdotally, we think there might be a mismatch between the experiences described above and the understandings of novice mentors. We suspect that people without professional practice research experience, even if they have postgraduate supervision experience, may fall back on what they know - conventional research approaches.

We expect this model to provide a basis for the languages required to underpin further improvement in professional practice learning and research, and for individual learners in planning and undertaking their research. 
Contact details: samuel.mann@op.ac.nz

Hase, S., \& Kenyon, C. (2000). From andragogy to heutagogy. Ulti-BASE In-Site, December. Retrieved from https://epubs.scu.edu.au/ gcm_pubs/99/.

Mann, S., Ker, G., Eden-Mann, P., \& O'Brien, R. (2017). Designing for heutagogy: Case study of an independent learning pathway approach. Scope (Teaching and Learning), 2, 59-70.

Scott, D., Brown, A., \& Lunt, I. (2004). Professional doctorates: Integrating academic and professional knowledge. London, UK: McGrawHill Education (UK).

Stock, C. F. (20 I I). Approaches to acquiring 'doctorateness' in the creative industries: An Australian perspective. In L. Justice \& K. Friedman (Eds.), Pre-Conference Proceedings: Doctoral Education in Design Conference 201 I (pp. I-I I). Hong Kong: Hong Kong Polytechnic University.

Wells, H., \& Smyth, H. (20I6). An Agile approach to the real experience of developing research methodology and methods. In B. Pasian (Ed.), Designs, Methods and Practices for Research of Project Management. Surrey, UK: Gower Publishing.

Zaitsev, A., Gal, U., \& Tan, B. (2018, August 16-18). Reviewing the role of the Agile manifesto and Agile methods in literature. Paper presented at 24th Americas Conference on Information Systems (AMCIS 20I8), New Orleans, US. Retrieved from https:// aisel.aisnet.org/amcis20 I 8/ITProjMgmt/Presentations/I3. 